\title{
Nanocrystalline 6061 Al Powder Fabricated by Cryogenic Milling and Consolidated via High Frequency Induction Heat Sintering
}

\author{
Walid Hanna, ${ }^{1}$ Khinlay Maung, ${ }^{1}$ Ehab A. El-Danaf, ${ }^{2}$ Abdulhakim A. Almajid, ${ }^{2,3}$ \\ Mahmoud S. Soliman, ${ }^{2}$ and Farghalli A. Mohamed ${ }^{1}$ \\ ${ }^{1}$ Materials Science, Department of Chemical Engineering and Materials Science, University of California Irvine, \\ Irvine, CA 92697, USA \\ ${ }^{2}$ Mechanical Engineering Department, College of Engineering, King Saud University, Riyadh 11421, Saudi Arabia \\ ${ }^{3}$ Center of Excellence for Research in Engineering Materials (CEREM), College of Engineering, King Saud University, \\ Riyadh 11421, Saudi Arabia
}

Correspondence should be addressed to Ehab A. El-Danaf; edanaf@ksu.edu.sa

Received 19 January 2014; Revised 20 April 2014; Accepted 22 April 2014; Published 12 May 2014

Academic Editor: Pavel Lejcek

Copyright (C) 2014 Walid Hanna et al. This is an open access article distributed under the Creative Commons Attribution License, which permits unrestricted use, distribution, and reproduction in any medium, provided the original work is properly cited.

Nanocrystalline $6061 \mathrm{Al}$ alloy was synthesized by cryogenic milling (cryomilling). Both transmission electron microscopy and X-ray diffraction were used to monitor the change in grain size as a function of milling time. The results of both techniques demonstrated a close agreement with respect to two observations: (a) during cryomilling, the grain size of $6061 \mathrm{Al}$ decreased with milling time, and (b) after $15 \mathrm{~h}$ of milling, the grain size approached a minimum value of about $22 \mathrm{~nm}$. Despite this agreement, there was a discrepancy: for grain sizes $>40 \mathrm{~nm}$, the grain size measured by transmission electron microscopy was appreciably larger than that inferred from X-ray diffraction. It was shown that powders consolidated via high frequency induction heat sintering (HFIHS) at 500 and $550^{\circ} \mathrm{C}$ maintained close to nanoscale grain sized microstructure in addition to high compact density in bulk samples. This was manifested by high strength values as compared to microscale grain samples.

\section{Introduction}

Nanocrystalline materials (nc-materials) [1-5], which are characterized by a grain size in the range of $1-100 \mathrm{~nm}$, have attracted both scientific and engineering interest. These materials have the potential of exhibiting a variety of unusual mechanical properties because of the high grain boundary fraction and changes in the grain interiors that are caused by the fine grain size.

Ball milling (BM) has been employed in recent years as a top-down method for processing nc-materials [6-9], which occurs as a result of structural decomposition. The refinement of grain size during ball milling is governed by deforming individual particles using the energy generated by ball collision in a milling medium either at room temperature or at a low temperature. The process of ball milling induces heavy cyclic deformation in powders and consists of repeated welding, fracturing, and rewelding of powder particles.
As a result, during milling, materials experience severe impact deformation, resulting in grain refinement. Over the past several years, the characteristics of crystal refinement and development of nanostructures during ball milling have been studied extensively. These studies have led to several important findings. First, Oleszak and Shingu [10] have observed that the crystallite size decreases with milling time leading to a minimum grain size, which is a characteristic of each metal. Eckert et al. [11] have suggested that the minimum average grain size, $d_{\min }$, is obtained as a result of a balance between the formation of dislocation structure and its recovery by thermal processes. Third, Fecht [12] has proposed a phenomenological approach for grain refinement during milling that involves the following three stages: (a) the localization of a high dislocation density in shear bands, (b) the annihilation and recombination of dislocations, forming cells and subgrains (recovery), and (c) the transformation of subboundaries into high grain boundaries. By utilizing 
the aforementioned findings and suggestions, Mohamed [13] has recently developed a theoretical dislocation model, which quantitatively describes the dependence of the minimum grain size on several physical parameters in an nc-material. The model may be represented by [13]

$$
\frac{d_{\min }}{b}=A_{3} \exp \left(-\frac{\beta Q}{4 R T}\right)\left(\frac{D_{P O} G b^{2}}{\nu_{o} k T}\right)^{0.25}\left(\frac{\gamma}{G b}\right)^{0.5}\left(\frac{G}{H}\right)^{1.25}
$$

where $b$ is the value of Burgers vector, $A_{3}$ is a dimensionless constant, $\beta$ is a constant $(\sim 0.04), Q$ is the self-diffusion activation energy, $R$ is the gas constant, $T$ is the absolute temperature, $D_{P O}$ is the frequency factor for pipe diffusion, $G$ is the shear modulus, $v_{o}$ is the initial dislocation velocity, $k$ is Boltzmann's constant, $\gamma$ is the stacking fault energy, and $H$ is the hardness ( $=3 \sigma$, where $\sigma$ is the normal stress). The presence of the stacking fault energy in (1) reflects the significant role played by this parameter in various dislocation activities involving cross slip [14] or dislocation climb [15-17].

As shown by (1), the model predicts that the minimum grain size, $d_{\min }$, depends on hardness, stacking fault energy, and an exponential function of the activation energy for recovery. The predictions of the above model were found to be in good agreement with experimental data reported for nc-FCC and nc-BCC metals [13]. Very recently, it has been shown [18] that the predictions of the model are consistent with characteristics of the minimum grain size obtainable in FCC and BCC metals by high-pressure torsion (HPT).

In this paper, experimental data obtained on grain size refinement in $6061 \mathrm{Al}$ via the technique of cryomilling are reported and analyzed. The investigation was motivated by two primary considerations as described herein.

First, $6061 \mathrm{Al}$ combines many of the attractive qualities of $\mathrm{Al}$ [19]. Not only does it possess high strength, high resistance to corrosion, good workability, and a wide range of mechanical properties but it also is the least expensive and most versatile of the heat treatable $\mathrm{Al}$ alloys. $6061 \mathrm{Al}$ contains magnesium as its major alloy element. As a result of this composition, the alloy has a density of $2.70 \mathrm{~g} / \mathrm{cm}^{3}$. The Al$\mathrm{Mg}$-Si $6061 \mathrm{Al}$ having a balanced ratio of $1 \%$ magnesium and $0.6 \%$ silicon to form $\mathrm{Mg}_{2} \mathrm{Si}$ has been set up as a standard for light-weight, economical material for general-purpose structural use. It contains an addition of $0.3 \%$ copper to achieve a higher strength in the T6 temper compared to copper free alloys with balanced composition in $\mathrm{Mg}$ and Si. While the technique of cryomilling was applied to the processing of several $\mathrm{Al}$ alloys such as $5083 \mathrm{Al}$, no detailed investigation in which $6061 \mathrm{Al}$ was cryomilled has so far been carried out.

Second, information on the minimum grain size obtainable in $\mathrm{Al}[10,20]$ via cryomilling is available. Such information, which was found to be consistent with the predictions of (1), could be used to provide a close comparison between the minimum grain size that characterizes the alloy and that reported for Al.

\section{Materials and Methods}

2.1. Materials. Nc-6061 Al powder was produced by mechanical milling in a liquid nitrogen medium. The as received powder of $6061 \mathrm{Al}$, with chemical composition (in wt.\%) of $1 \mathrm{Mg}, 0.6 \mathrm{Si}$, and $0.3 \mathrm{Cu}$, had an average particle size of about $50 \mu \mathrm{m}$. The chemical analysis was carried out by Luvak Inc., a professional chemical analysis company located in Boylston, MA.

\subsection{Methods}

2.2.1. Cryomilling and Characterization of Milled Powders. The powders were milled in a modified union process attritor at a rate of $180 \mathrm{rpm}$ in stainless steel tank containing stainless steel balls of $6.4 \mathrm{~mm}$ in diameter, which were used as the grinding media. The ball-to-powder weight ratio was 30 to 1. The temperature in the vial was $-183^{\circ} \mathrm{C}(90 \mathrm{~K})$. During the milling operation that lasted 15 hours, liquid nitrogen was added directly into the mill to maintain complete immersion of the milling media. A sample was taken after one hour and then every 2 hours to check the effect of the milling time on the grain size. Prior to milling, approximately $0.2 \mathrm{wt} \%$ stearic acid $\left[\mathrm{CH}_{3}\left(\mathrm{CH}_{2}\right)_{16} \mathrm{COOH}\right]$ was added to the powders as a process control agent to prevent adhesion of the powders to the milling tools during the process.

Three techniques, X-ray diffraction (XRD), transmission electron microscopy (TEM), and scanning electron microscopy (SEM), were used to investigate the microstructure of the material. Both XRD and TEM were used to provide grain size measurements as a function of time. While XRD yields the values of the average grain size, TEM has the advantage of providing the distribution of grain size, from which the average grain size can be estimated. In addition, TEM and SEM were utilized to check the development of the nanostructure during cryomilling.

XRD measurements were carried out with a Rigaku SmartLab X-ray Diffractometer using $\mathrm{Cu} \mathrm{K}_{\alpha}$ radiation $(\lambda=$ $0.1542 \mathrm{~nm}$ ) at 100 steps per degree and a count time of 10 seconds per step. The grain size and lattice microstrain were determined via the integral breadths (IB) method described elsewhere [22]. TEM sample preparation consisted of suspending the nanostructured powders in ethanol, agitating the solution by hand, and submersing a $\mathrm{Cu}$ TEM grid into the ethanol where the powders adhered to it. This method has an advantage over the cold-compaction method [23] in terms of minimizing the effects of sample preparation on the microstructures and morphologies of the milled powders. In the cold-compaction method [23], the powders are consolidated to a bulk pellet under very high pressures (usually more than $1 \mathrm{GPa}$ ). As a result, additional severe plastic deformation is introduced into the material. In this case, the microstructure observed may not represent that characterizing as-milled condition. Micrographs of the powders were produced using a Philips CM20 transmission electron microscope operated at $200 \mathrm{kV}$. Average grain size was determined directly from the TEM micrographs by measuring the diameters of about 250 grains for each sample using Image $\mathrm{J}$ image analysis software. 
TABle 1: Chemical composition (wt.\%) of the starting and cryomilled powders.

\begin{tabular}{lcc}
\hline $\begin{array}{l}\text { Chemical } \\
\text { analysis }\end{array}$ & Al 6061 as received & Al 6061 after cryomilling \\
\hline $\mathrm{Zn}$ & 0.06 & 0.03 \\
$\mathrm{Ti}$ & 0.01 & 0.02 \\
$\mathrm{Si}$ & 0.52 & 0.53 \\
$\mathrm{Mg}$ & 1.03 & 0.9 \\
$\mathrm{Mn}$ & 0.03 & 0.03 \\
$\mathrm{Fe}$ & 0.27 & 0.5 \\
$\mathrm{Cu}$ & 0.25 & 0.23 \\
$\mathrm{Cr}$ & 0.09 & 0.08 \\
$\mathrm{C}$ & 0.96 & 1.4 \\
$\mathrm{~N}$ & - & 1.38 \\
O & 2.61 & 2.8 \\
Other each & $<0.05$ & $<0.05$ \\
Other total & $<0.15$ & $<0.15$ \\
Al & Balance & Balance \\
\hline
\end{tabular}

2.2.2. Consolidation of Cryomilled Powders. After an intended milling time of $7 \mathrm{hrs}$, the powders were collected in slurry form from a valve underneath the milling vial. The slurry was then dried in a drying vacuum oven at a temperature of $250^{\circ} \mathrm{C}$ and a vacuum level of $\sim 10^{-4}$ torr for 3 hours. The dried powders were charged into a graphite die $10 \mathrm{~mm}$ in diamater between two fitting punches. The die was placed in a high frequecy induction heat sintering press under a constant pressure of $50 \mathrm{MPa}$ in a vacuum chamber of $10^{-3}$ torr. The induced current frequency was approximately $50 \mathrm{kHz}$. Two sintering temperatures of 500 and $550^{\circ} \mathrm{C}$ were investigated while maintaining the heating rate and sintering dwell time at $400^{\circ} \mathrm{C} / \mathrm{min}$ and 1.5 minutes, respectively. The crystal size was checked after consolidation using the X-ray line broadening.

The density of consolidated samples was measured by means of Archimedes' principle. Hardness measurements were done using a Vickers microhardness test machine. A load of $200 \mathrm{~g}$ and a dwell time of $15 \mathrm{sec}$ were used. Five measurements were taken across the face of the consolidated samples, and the average value is reported. The mechanical behavior of consolidated samples was investigated by compression testing using an Instron universal testing machine (model 3385) at room temperature and $200^{\circ} \mathrm{C}$ and at a crosshead speed that corresponds to an initial strain rate of $1 \mathrm{~s}^{-1}$.

\section{Results and Discussion}

3.1. Chemical Composition. Information given in Table 1 provides the chemical composition of the initial powder and that after milling. An examination of this information shows that, after milling for $15 \mathrm{~h}$, amounts of impurity elements, such as carbon, nitrogen, oxygen, and iron, were introduced. Oxygen most probably originated from the as received powder and condensation or oxidation of the milled powders. On the other hand, nitrogen was introduced into the powder because milling was conducted in liquid nitrogen. Iron and carbon originated from wear of the stainless steel milling media and chamber components. Also, carbon and oxygen can be introduced from stearic acid, which, as mentioned earlier, was added as a process control agent. The reason for the high amounts of oxygen and nitrogen is that the process of degassing was not carried out after the completion of the process of milling. As indicated by the data, the amount of $\mathrm{Mg}$ decreased slightly.

3.2. Morphology of Milled Powders. Figure 1 shows typical SEM micrographs for the initial and milled powder. In the early milling stages, the majority of the powder particles changed from spheres to thin disk-shaped particles. The thickness of the thin disks ranged from 2 to $10 \mu \mathrm{m}$. At the end of milling, the powder assumed an approximate spherical morphology again.

Milling is a repetitive process that involves cold welding and fracturing of powder particles. The rate of cold welding is predominant in the early stages of milling. Accordingly, the majority of the powder particles change from spheres to thin disk-shaped particles because of the high degree of plastic deformation resulting from the impact energy during ball-powder-ball collisions. In the later stages of milling, the rate of fragmentation is predominant. At the end of the milling process, the powders assume a spherical shape, which signifies the attainment of a balance between the rate associated cold-welding and that with fracture.

3.3. Grain Size. Examination of XRD spectra of the powders for different milling times shows that with increasing milling time XRD peaks, (111) and (220), broaden and decrease drastically as indicated by Figure 2 . The broadening of Bragg peaks is caused by the small size of the diffracting grains and by the internal lattice strain. As mentioned in Section 2, XRD measurements were carried out with a Rigaku SmartLab Xray Diffractometer, in which, when calibrated by standard sample, no correction for instrumental broadening is necessary. The equation that describes the dependence of the measured peak width $(\delta s)$ on the volume averaged grain size, $d$, the internal strain, $e$, and the reciprocal space variable, $s$ $(s=2 \sin \theta / \lambda)$, can be represented by $[24,25]$

$$
\frac{K}{(\delta s) L}=1-\left[\frac{2 e s}{\delta s}\right]^{2} .
$$

Taking $L=$ grain size $=d$ and $K=1$ and rearranging (2a) lead to

$$
\frac{1}{(\delta s)}=d-4 d e^{2}\left[\frac{s}{\delta s}\right]^{2} .
$$

On the basis of (2b), the grain size, $d$, was determined by (a) plotting $(1 / \delta s)$ against $(s / \delta s)^{2}$ for all of the measured peaks and (b) performing a least-square fit. Standard linear regression techniques provide an estimate of the uncertainty in the parameters from the error in the fit.

During cryomilling, the $d$ values of $6061 \mathrm{Al}$, as inferred from XRD measurements, decreased rapidly in the first hours 

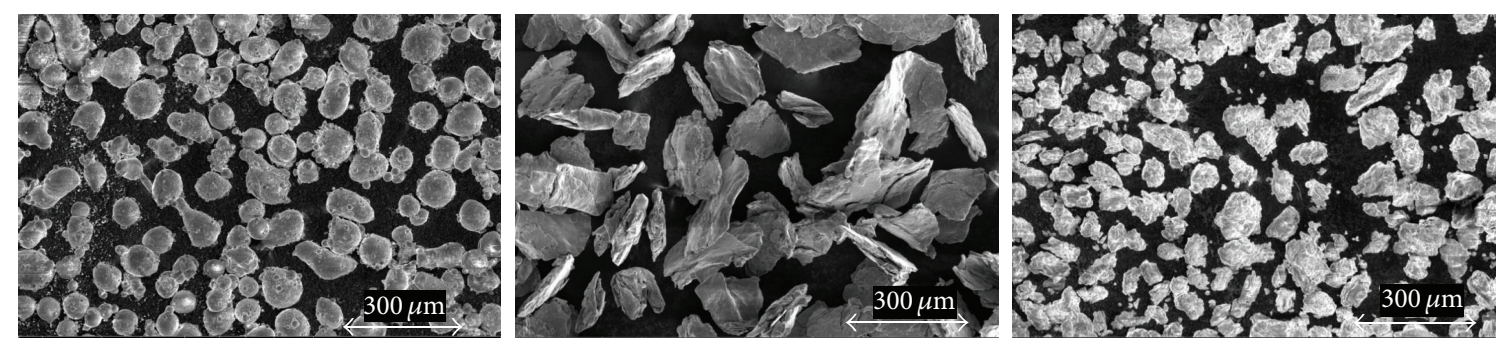

FIGURE 1: Morphlogy of the powders (SEM): (a) as received, (b) cryomilled $1 \mathrm{~h}$, and (c) cryomilled $15 \mathrm{~h}$.

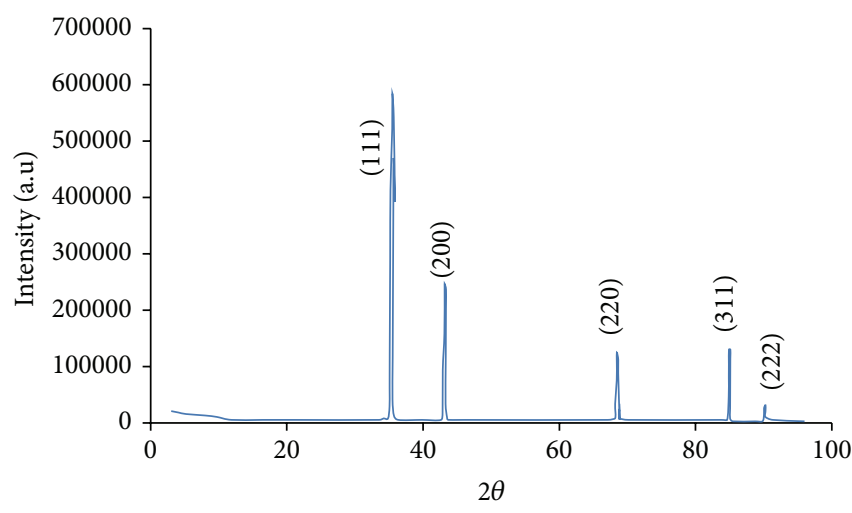

(a)

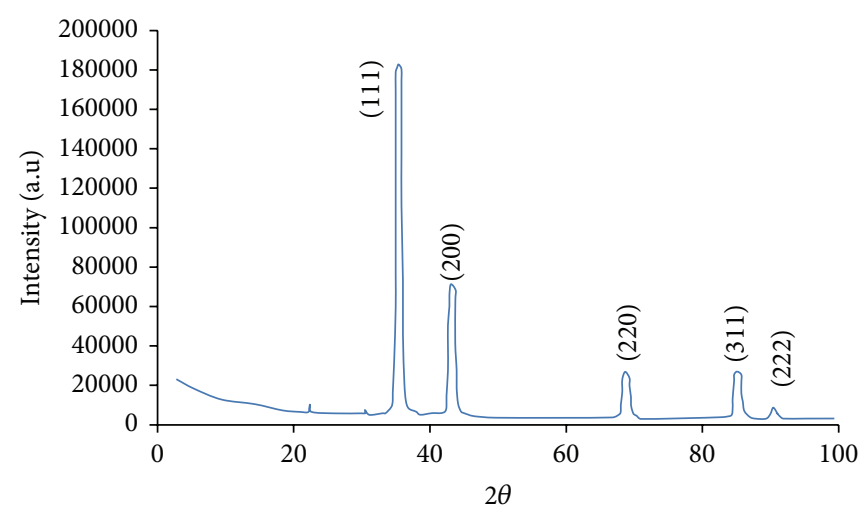

(b)

FIGURE 2: XRD patterns for the cryomllied $6061 \mathrm{Al}$ : (a) as received and (b) cryomilled $15 \mathrm{~h}$.

of milling and then decreased much slowly at long milling times. After $15 \mathrm{~h}$ of milling, the grain size decreased and approached a minimum value, $d_{\min }$, of $20 \mathrm{~nm}$. The error in these measurements was $\leq 10 \%$ of the reported values.

The value of lattice strain in $6061 \mathrm{Al}$ after milling for $15 \mathrm{~h}$ was 0.25 . According to the data given in Table $2[10,11,20,21]$, this value for lattice strain in the alloy is higher than those reported for Al; the lower limit for the 6061 alloy in the present study after the $15 \mathrm{~h}$ milling time, taking the maximum negative error into consideration, is 0.22 which is higher than the higher limit of 0.20 for the aluminum metal after $20 \mathrm{~h}$ of milling time [11]. According to this finding, it appears possible that the presence of $\mathrm{Mg}$ in $\mathrm{Al}$ during milling may lead to an enhancement in the value of lattice strain. There are two observations that tend to support this possibility. First, the dislocation density increases significantly [23] when $\mathrm{Mg}$ is present in $\mathrm{Al}$ powder. Second, as reported elsewhere [11], one of the primary sources for lattice strains during ball milling is related to the generation of dislocations as a result of severe plastic deformation. Despite these observations, the above possibility needs to be explored systematically since the lattice strain reported for $\mathrm{Al}-7.5 \mathrm{Mg}$ (Table 2) is comparable within experimental errors to that measured in $606 \mathrm{Al}$, which contains only $1.0 \% \mathrm{Mg}$.

Examination of representative TEM micrographs (bright field) along with selected area diffraction (SAD) patterns such as those given in Figure 3 indicated that the average size of the equiaxed crystallites decreased with milling time. It is worth mentioning that grains are not clearly visible in some regions of the typical bright field TEM images of the powder cryomilled for $15 \mathrm{~h}$, basically as a result of the high residual strain often observed in materials processed by serve plastic deformation.

Histograms of the grain size distribution were constructed using a number of representative TEM micrographs. In constructing each histogram, about 250 grains were used. Typical examples for TEM histograms are shown in Figures $4(\mathrm{a})$ and 4 (b) for milling times of $1 \mathrm{~h}$ and $15 \mathrm{~h}$, respectively. By using these histograms, it was possible to estimate the average grain size as a function of milling time.

Figure 5 provides a comparison between the averages of grain size as measured by XRD and those inferred from the TEM histograms. An examination of the figure reveals that while the measurements by XRD and TEM are similar in terms of trend (grain size decreases with milling time) and the value of the minimum grain size (for XRD, $d=20 \mathrm{~nm}$ and for TEM, $d=23 \mathrm{~nm}$ ), there are two significant differences: (a) at milling times $<13 \mathrm{hr}$, there is a discrepancy between the values of $d$ inferred from TEM and those estimated from XRD peaks and (b) the extent of such a discrepancy increases with decreasing milling time. The reason for the discrepancy is that the technique of XRD cannot provide accurate measurements for grains sizes whose values > $100 \mathrm{~nm}$ [26] and as a result using this technique would lead to an underestimation of the average grain size.

Grain size is an important microstructural parameter that has been used in identifying various deformation mechanisms (for deformation mechanisms involving dislocation 
TABLE 2: The average grain size and lattice strains in $\mathrm{nc}-\mathrm{Al}$ and its alloys produced by ball milling.

\begin{tabular}{|c|c|c|c|c|c|}
\hline Material & Milling time (h) & $d(\mathrm{~nm})$ & $\left(e^{2}\right)^{1 / 2}(\%)$ & $T(\mathrm{~K})$ & Reference \\
\hline $\mathrm{Al}$ & $\sim 20$ & $22 \pm 2$ & $0.18 \pm 0.02$ & 298 & [11] \\
\hline $\mathrm{Al}$ & $\sim 100$ & $\sim 25$ & $\sim 0.16$ & 298 & {$[10]$} \\
\hline $\mathrm{Al}$ & 8 & $26 \pm 2$ & $0.16 \pm 0.03$ & 90 & {$[20]$} \\
\hline $\mathrm{Al}-7.5 \mathrm{Mg}$ & 8 & $22 \pm 2$ & $0.20 \pm 0.03$ & 90 & {$[21]$} \\
\hline $\mathrm{Al}-7.5 \mathrm{Mg}-0.3 \mathrm{Sc}$ & 8 & $26 \pm 2$ & $0.23 \pm 0.03$ & 90 & {$[21]$} \\
\hline $\mathrm{Al} 6061$ & 15 & $23 \pm 2$ & $0.25 \pm 0.03$ & 90 & This work \\
\hline
\end{tabular}
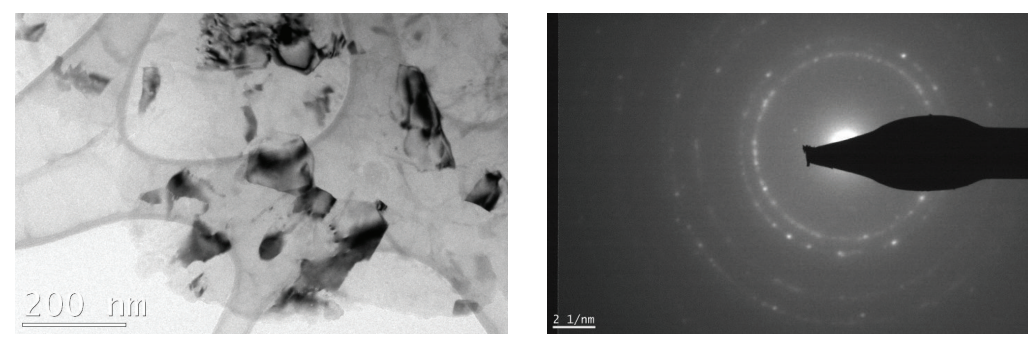

(a)
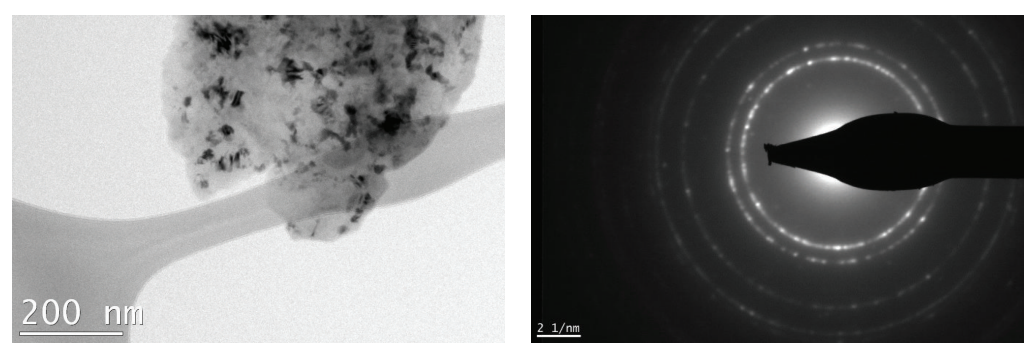

(b)

FIGURE 3: Microstructures of the powders of $6061 \mathrm{Al}$ (bright field TEM and selected area diffraction SAD): (a) cryomilled 1h and (b) cryomilled $15 \mathrm{~h}$.

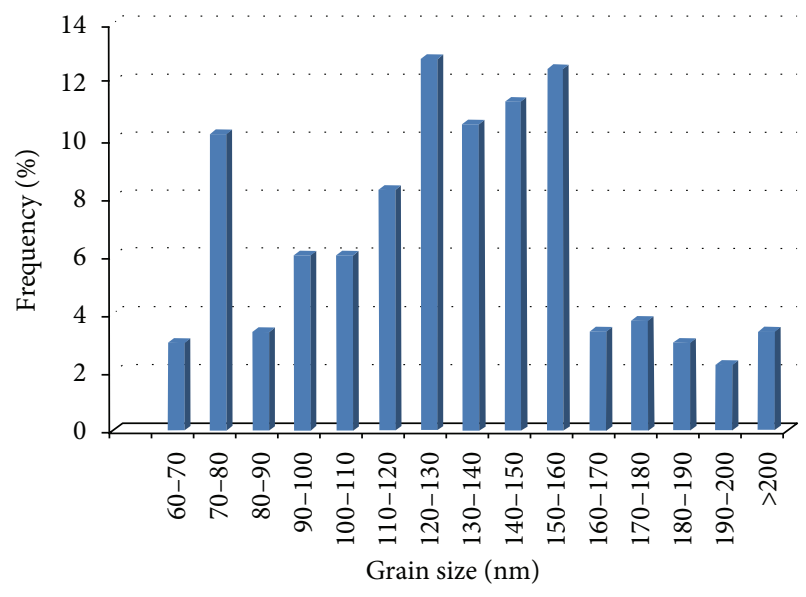

(a)

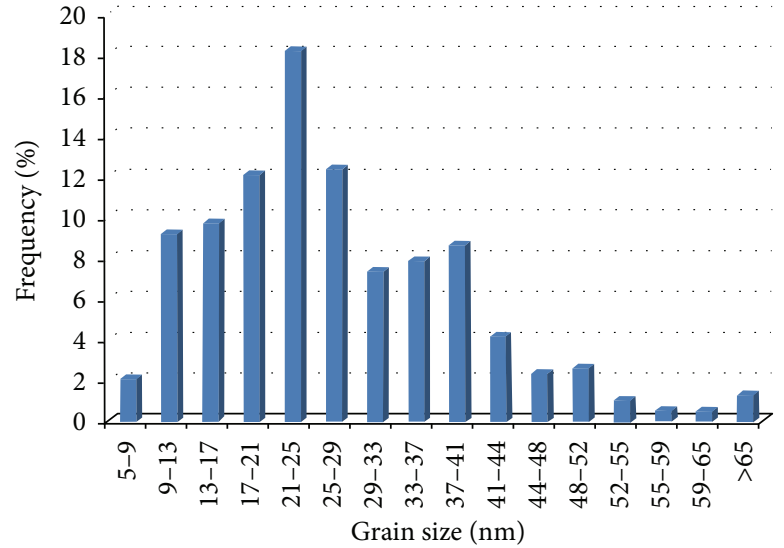

(b)

FIGURE 4: Histograms for grain size distribution in the powders of $6061 \mathrm{Al}$ : (a) cryomilled $1 \mathrm{~h}$ and (b) cryomilled $15 \mathrm{~h}$. 


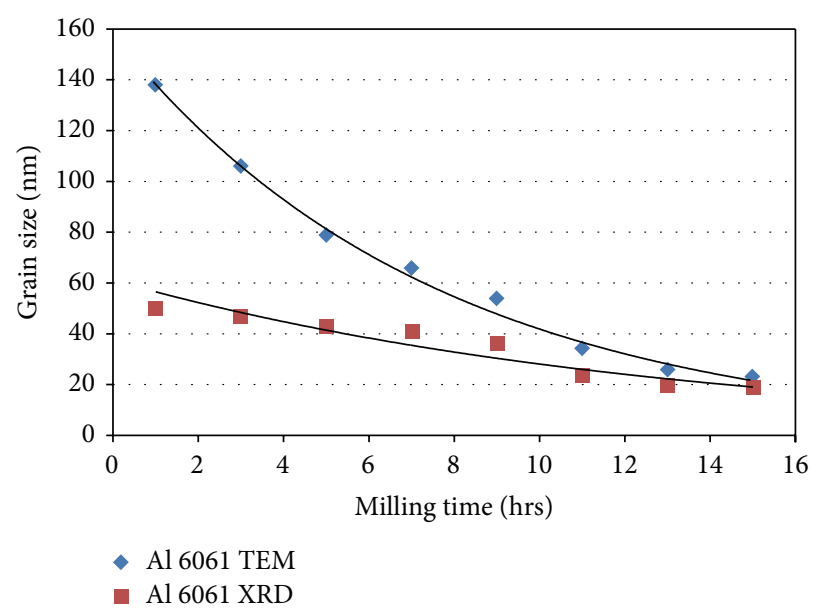

FIGURE 5: Grain size of the cryomilled $6061 \mathrm{Al}$ powders as a function of milling time. Data are calculated using XRD and TEM separately.

activity in the interiors of grains, the exponent of grain size, $p$, is 0 while for grain boundary processes, $p \geq 1$ ) and constructing deformation maps [27]. The minimum grain size in (1) reflects the attainment of a balance between the formation of dislocation structure and its recovery by thermal processes [13]. It is not possible to predict the minimum grain size of $6061 \mathrm{Al}$ using (1) since the values of the staking fault energy and the activation energy for diffusion in the alloy (the alloy has $\mathrm{Mg}$, $\mathrm{Si}$, and $\mathrm{Cu}$ ) are not exactly known. However, data on the minimum grain size obtained in $\mathrm{Al}[10,11,20]$ and some of its alloys [21] via cryomilling are available and given in Table 2. It is clear that the value of the minimum grain size in $6061 \mathrm{Al}$ (about $23 \mathrm{~nm}$ by TEM) agrees well with those reported for $\mathrm{Al}$. The value of the minimum grain size in 6061 is larger than that reported for $5083 \mathrm{Al}(16 \mathrm{~nm})$, which was estimated from XRD peaks [28].

The rate at which the grain size decreases during milling is related to the deformation energy provided by milling [13]. This energy is a measure of plastic deformation via dislocation multiplication and motion. The deformation energy is a function of stress and can, to a first approximation, be given by

$$
U=\int \sigma d \varepsilon
$$

Equation (3) can be integrated and expressed in terms of strain if the relation between stress and strain is known [13]. The strain imposed in powder materials by some severe deformation processes can be estimated from geometry changes in case of equal channel angular pressing (ECAP) $[29,30]$ and high-pressure torsion (HPT) [29]. By contrast, strain experienced by powder materials during ball milling cannot be easily followed based on geometry change, in part due to the nonuniformity of starting powder particles and in part due to the extensive fracturing and rewelding occurring randomly during milling [31]. As a result, the change in grain size is commonly characterized by plotting grain size as a function of milling time as shown in Figure 5. However, it is possible to crudely estimate the lower bound of the strain by using the powder geometry change as performed in [29].
A close inspection of the shape of $6061 \mathrm{Al}$ powders as a function of milling time indicated that, after milling for $3 \mathrm{hr}$, the contribution of the process of rewelding could be assumed to be very small and that deformation is mostly responsible for producing the shape of the particles. By taking the average starting powder size as $55 \mu \mathrm{m}$ and average disc thickness of $5.6 \mu \mathrm{m}$ after milling to $3 \mathrm{hrs}$, a true strain of 2.3 was estimated. This true strain of 2.3 is equivalent to an engineering strain of $1000 \%$. Despite the crude nature of the estimation of the lower bound of the strain involved in ball milling of $6061 \mathrm{Al}$, such an estimate demonstrates that strains involved in the milling process are large. In fact, it has been reported that ball milling can be approximately associated with a lower bound for the true strain as large as 4.5 , which is equivalent to an engineering strain of about $9000 \%$.

3.4. Consolidation of 6061 Al through High Frequency Induction Heat Sintering (HFIHS). It should be mentioned that while cryomilling of $6061 \mathrm{Al}$ produces milled powder having an average grain size of about $23 \mathrm{~nm}$ (estimated from TEM measurements), consolidation of the powder, which is usually performed at high temperatures, leads to grain growth beyond the nc-regime grains. Very recently, it was demonstrated that bulk nc-Al samples whose grain sizes are less than $100 \mathrm{~nm}$ can be produced by consolidating cryomilled Al powders containing diamantane [32], whose size is in the range $2-5 \mathrm{~nm}$, via hot isostatic pressing (HIP) followed by trap extrusion (high strain extrusion) at room temperature and that the average grain size for cryomilled bulk nc-Al containing diamantane was consistently about one half $(69 \mathrm{~nm})$ of that for the powders that do not contain diamantane at the same temperature $(150 \mathrm{~nm})$ [33].

In the current investigation, powders cryomilled for 7 hours which yielded an average grain size of about $65 \mathrm{~nm}$ as estimated by TEM and $40 \mathrm{~nm}$ by XRD were consolidated via HFIHS for two sinetring temperatures of $500^{\circ} \mathrm{C}$ and $550^{\circ} \mathrm{C}$, in which the heating rate and sintering dwell time were maintained constant at $400^{\circ} \mathrm{C} / \mathrm{min}$ and 1.5 minutes, respectively. The consloidated samples were examined for 
TABle 3: Properties of the consolidated samples.

\begin{tabular}{lccc}
\hline Sintering parameters & $\begin{array}{c}\text { Grain } \\
\text { size } \\
(\mathrm{nm})\end{array}$ & $\begin{array}{c}\text { Percentage of } \\
\text { full density } \\
(\%)\end{array}$ & $\begin{array}{c}\text { Hardness } \\
\mathrm{HV}\end{array}$ \\
\hline $500^{\circ} \mathrm{C}-400^{\circ} \mathrm{C} / \mathrm{min}-1.5 \mathrm{~min}$. & 125 & 92 & 56 \\
$550^{\circ} \mathrm{C}-400^{\circ} \mathrm{C} / \mathrm{min}-1.5 \mathrm{~min}$. & 150 & 98 & 59 \\
\hline
\end{tabular}

three aspects: density, hardenss, and crystal size by X-ray line broadneing as mentioned earlier. Table 3 summarizes these results. Both consolidated samples exhibited a grain size above $100 \mathrm{~nm}\left(125 \mathrm{~nm}\right.$ for $500^{\circ} \mathrm{C}$ and $150 \mathrm{~nm}$ for the $\left.550^{\circ} \mathrm{C}\right)$. Higher densification for the $550^{\circ} \mathrm{C}$ sample $(98 \%$ of full density compared to $92 \%$ for the $500^{\circ} \mathrm{C}$ consolidated sample) was observed. These consolidated samples, which were cylindrical with $10 \mathrm{~mm}$ in diameter and height, were tested in simple compression at room temperature as well as at $200^{\circ} \mathrm{C}$ to check for thermal stability. True stress strain response was calcualted after correcting the load displacment data for machine compliance. All compression testing was performed at an initial strain rate of $1 \mathrm{~s}^{-1}$. Figure 6 presents the true stress strain response for 6061 consolidated at a sintering temperature of $500^{\circ} \mathrm{C}$, heating rate of $400^{\circ} \mathrm{C} / \mathrm{min}$, and sintering time of $1.5 \mathrm{~min}$, compared to the response of 6061 AA bulk sample consolidated under the same sinetring conditions from the as recieved powders. It is obvious the higher yield strength for the bulk material was produced by cryomilling and subsequent consolidation. Figure 7 represents the true stress strain response for the same consolidated sample (same sintering conditrions mentioned above $500^{\circ} \mathrm{C} / 400 / 1.5$ ) at room temeprature as well as at $200^{\circ} \mathrm{C}$. The samples were soaked at the respective temperatrue for 15 minutes between the compression anvils before compression testing started. Figure 8 presents the true stress strain response obtained for the other sinetring conditon $\left(550^{\circ} \mathrm{C} / 400 / 1.5\right)$. The compression was, again, done at room temeprature and $200^{\circ} \mathrm{C}$. The close behavior of the samples at room temperature and $200^{\circ} \mathrm{C}$ suggests acceptable thermal stability of the consolisdated microstructure.

Previous work on the consolidating of cryomilled 99.7 Al powders using high frequency induction heat sintering reported bulk nanostructured samples (grain size $<100 \mathrm{~nm}$ ) for some of the sintering conditions [34]. Other works using spark plasma sintering [35], also, resulted in bulk samples of nanoscale structure in $\mathrm{Al}$ alloys. The aforementioned two sintering techniques are characterized by high heating rates and short dwell time (few minutes).

Future research will focus on adopting the above approach (adding diamantine during milling and/or using other sintering techniques) to $\mathrm{Al}$ alloys such as $6061 \mathrm{Al}$ to examine whether the grain size of cryomilled $\mathrm{Al}$ alloys would remain in the nanoscale range after consolidation.

\section{Conclusions}

(1) XRD and TEM observations clearly indicate that cryomilling is effective in producing nc-6061 Al. For

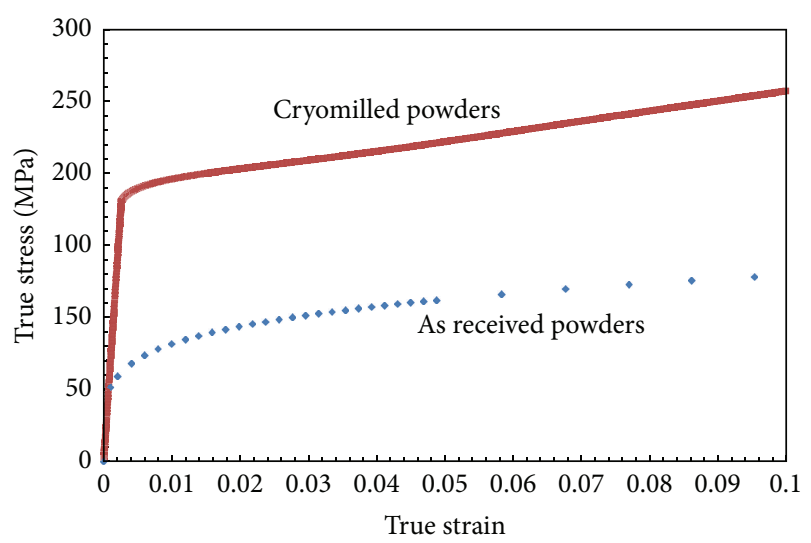

FIgURE 6: True stress strain response in simple compression for consolidated samples from the 7 hours cryomilled powders of 6061 $\mathrm{Al}$ and as received powders at the sintering conditions of $500^{\circ} \mathrm{C}-$ $400^{\circ} \mathrm{C} / \mathrm{min}-1.5 \mathrm{~min}$.

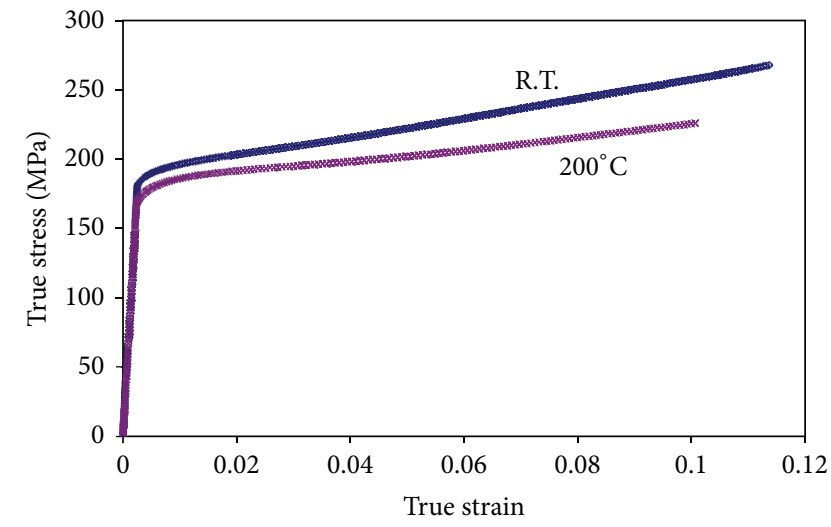

FIGURE 7: True stress strain response in simple compression for consolidated samples from the 7 hours cryomilled powders of 6061 $\mathrm{AA}$ at the sintering conditions of $500^{\circ} \mathrm{C}-400^{\circ} \mathrm{C} / \mathrm{min}-1.5 \mathrm{~min}$ at a strain rate of $1 \mathrm{~s}^{-1}$ at room temperature and $200^{\circ} \mathrm{C}$.

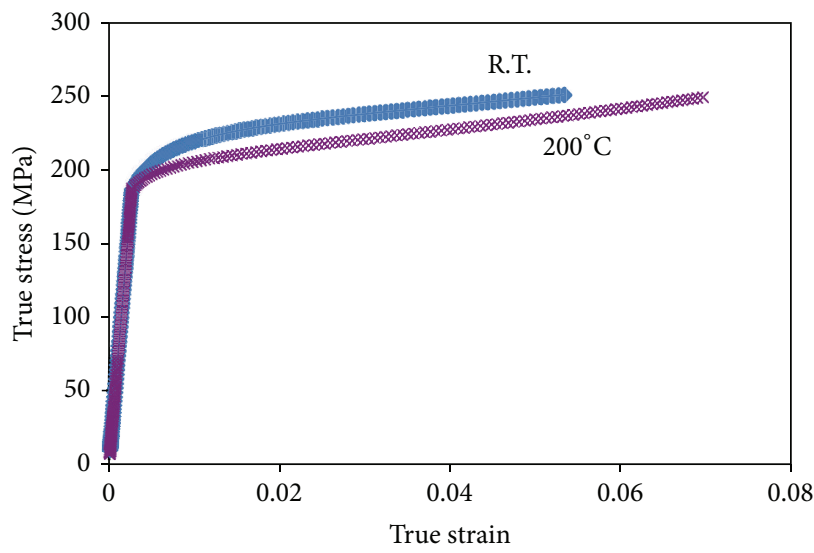

Figure 8: True stress strain response in simple compression for consolidated samples from the 7 hours cryomilled powders of 6061 $\mathrm{AA}$ at the sintering conditions of $550^{\circ} \mathrm{C}-400^{\circ} \mathrm{C} / \mathrm{min}-1.5 \mathrm{~min}$ at a strain rate of $1 \mathrm{~s}^{-1}$ at room temperature and $200^{\circ} \mathrm{C}$. 
example, the selected-area diffraction (SAD) pattern is typical of nanostructured materials.

(2) After $15 \mathrm{~h}$ of cryomilling, the grain size approached a minimum value, $d_{\text {min }}$, of about $23 \mathrm{~nm}$ (TEM measurements), which is comparable to the values reported for $\mathrm{Al}$.

(3) The grain size measurements by XRD and TEM are similar in terms of trend (grain size decreases with milling time) and the value of the minimum grain size (for XRD, $d=20 \mathrm{~nm}$ and for TEM, $d=23 \mathrm{~nm}$ ). Despite the agreement in trend and the value of the minimum grain size, there are two significant differences: (a) at milling times $<13 \mathrm{~h}$, there is a discrepancy between the values of $d$ inferred from TEM and those estimated from XRD peaks and (b) the extent of such a discrepancy increases with decreasing milling time. Such a discrepancy is explained in terms of the inability of the technique of XRD to provide accurate measurements for grains sizes whose values $>100 \mathrm{~nm}$.

(4) A crude estimate of the lower bound of the strain experienced by the $6061 \mathrm{Al}$ powder after milling for $3 \mathrm{~h}$ yields an engineering strain as large as $1000 \%$.

(5) Consolidation of cryomilled powders with grain size $\sim 40 \mathrm{~nm}$ by high frequency induction heat sintering at 500 and $550 \circ \mathrm{C}$ with a heating rate of $400 \circ \mathrm{C} / \mathrm{min}$ and sintering dwell time of 1.5 minutes resulted in bulk materials with more than $90 \%$ densification and crystal size of 125 and $150 \mathrm{~nm}$, respectively. The bulk-consolidated material exhibited an acceptable thermal stability at $200 \circ \mathrm{C}$ by comparing the stress strain response.

\section{Conflict of Interests}

The authors declare that there is no conflict of interests regarding the publication of this paper.

\section{Acknowledgments}

This work was financially supported by the National, Science, Technology, and Innovation Plan (NSTIP), Strategic Technologies Programs, Kingdom of Saudi Arabia, under Project no. 08-ADV-394-02. Also one of the authors (Walid Hanna) would like to thank the Military Technical College, Cairo, Egypt, for personal financial support.

\section{References}

[1] H. Gleiter, "Nanostructured materials: basic concepts and microstructure," Acta Materialia, vol. 48, no. 1, pp. 1-29, 2000.

[2] H. Gleiter, "Nanocrystalline materials," Progress in Materials Science, vol. 33, no. 4, pp. 223-315, 1989.

[3] J. R. Weertman, "The pursuit of the small: from grain-boundary cavities to nanocrystalline metals," MRS Bulletin, vol. 29, no. 9, pp. 616-620, 2004.

[4] F. A. Mohamed and Y. Li, "Creep and superplasticity in nanocrystalline materials: current understanding and future prospects," Materials Science and Engineering A, vol. 298, no. 1-2, pp. 1-15, 2001.

[5] M. A. Meyers, A. Mishra, and D. J. Benson, "Mechanical properties of nanocrystalline materials," Progress in Materials Science, vol. 51, no. 4, pp. 427-556, 2006.

[6] C. Suryanarayana:, Mechanical Alloying and Milling, Marcel Dekker, New York, NY, USA, 2004.

[7] D. B. Witkin and E. J. Lavernia, "Synthesis and mechanical behavior of nanostructured materials via cryomilling," Progress in Materials Science, vol. 51, no. 1, pp. 1-60, 2006.

[8] C. C. Koch, "Synthesis of nanostructured materials by mechanical milling: problems and opportunities," Nanostructured Materials, vol. 9, pp. 13-22, 1997.

[9] E. J. Lavernia, B. Q. Han, and J. M. Schoenung, "Cryomilled nanostructured materials: processing and properties," Materials Science and Engineering A, vol. 493, no. 1-2, pp. 207-214, 2008.

[10] D. Oleszak and P. H. Shingu, "Nanocrystalline metals prepared by low energy ball milling," Journal of Applied Physics, vol. 79, no. 6, pp. 2975-2980, 1996.

[11] J. Eckert, J. C. Holzer III, C. E. Krill, and W. L. Johnson, "Structural and thermodynamic properties of nanocrystalline fcc metals prepared by mechanical attrition," Journal of Materials Research, vol. 7, no. 7, pp. 1751-1761, 1992.

[12] H. J. Fecht, "Nanostructure formation by mechanical attrition," Nanostructured Materials, vol. 6, no. 1-4, pp. 33-42, 1995.

[13] F. A. Mohamed, "A dislocation model for the minimum grain size obtainable by milling," Acta Materialia, vol. 51, no. 14, pp. 4107-4119, 2003.

[14] J. Friedel, Dislocations, Pergamon Press, Oxford, UK, 1964.

[15] A. K. Mukherjee, J. E. Bird, and J. E. Dorn, "Cones and VietorisBegle type theorems," Transactions of the American Society of Metals, vol. 62, pp. 155-174, 1969.

[16] O. D. Sherby and P. M. Burke, "Mechanical behavior of crystalline solids at elevated temperature," Progress in Materials Science, vol. 13, pp. 323-390, 1968.

[17] F. A. Mohamed and T. G. Langdon, "Method of estimating stacking-fault energies in alkali halide crystals using creep data," Journal of Applied Physics, vol. 45, no. 5, pp. 1965-1967, 1974.

[18] F. A. Mohamed and S. S. Dheda, "On the minimum grain size obtainable by high-pressure torsion," Materials Science and Engineering A, vol. 558, pp. 59-63, 2012.

[19] Metals Handbook, Properties and Selection: Non Ferrous Alloys and Pure Metals, vol. 2, 9th edition, 1979.

[20] F. Zhou, D. Witkin, S. R. Nutt, and E. J. Lavernia, "Formation of nanostructure in $\mathrm{Al}$ produced by a low-energy ball milling at cryogenic temperature," Materials Science and Engineering A, vol. 375-377, no. 1-2, pp. 917-921, 2004.

[21] F. Zhou, S. R. Nutt, C. C. Bampton, and E. J. Lavernia, "Nanostructure in an Al-Mg-Sc alloy processed by low-energy ball milling at cryogenic temperature," Metallurgical and Materials Transactions A: Physical Metallurgy and Materials Science, vol. 34, no. 9, pp. 1985-1992, 2003.

[22] F. A. Mohamed and Y. Xun, "On the minimum grain size produced by milling Zn-22\%Al," Materials Science and Engineering $A$, vol. 358, no. 1-2, pp. 178-185, 2003.

[23] X. Z. Liao, J. Y. Huang, Y. T. Zhu, F. Zhou, and E. J. Lavernia, "Deformation mechanisms at different grain sizes in a cryogenically ball-milled Al-Mg alloy," in Ultrafine Grained Materials II, pp. 323-330, usa, February 2002. 
[24] H. P. Klug and L. Alexander, X-Ray Diffraction Procedures for Polycrystalline and Amorphous Materials, John Wiley, New York, NY, USA, 1974.

[25] Z. Zhang, F. Zhou, and E. J. Lavernia, "On the analysis of grain size in bulk nanocrystalline materials via x-ray diffraction," Metallurgical and Materials Transactions A: Physical Metallurgy and Materials Science, vol. 34, no. 6, pp. 1349-1355, 2003.

[26] C. E. Krill and R. Birringer, "Estimating grain-size distributions in nanocrystalline materials from X-ray diffraction profile analysis," Philosophical Magazine A: Physics of Condensed Matter, Structure, Defects and Mechanical Properties, vol. 77, no. 3, pp. 621-640, 1998.

[27] T. G. Langdon and F. A. Mohamed, "A new type of deformation mechanism map for high-temperature creep," Materials Science and Engineering, vol. 32, no. 2, pp. 103-112, 1978.

[28] V. L. Tellkamp, S. Dallek, D. Cheng, and E. J. Lavernia, "Grain growth behavior of a nanostructured $5083 \mathrm{Al}-\mathrm{Mg}$ alloy," Journal of Materials Research, vol. 16, no. 4, pp. 938-944, 2001.

[29] Y. Xun and F. A. Mohamed, "Refining efficiency and capability of top-down synthesis of nanocrystalline materials," Materials Science and Engineering A, vol. 528, no. 16-17, pp. 5446-5452, 2011.

[30] Y. I. Wahashi, J. Wang, Z. Horita, M. Nemoto, and T. G. Langdon, "Principle of equal-channel angular pressing for the processing of ultra-fine grained materials," Scripta Materialia, vol. 35, no. 2, pp. 143-146, 1996.

[31] T. D. Shen and C. C. Koch, "The influence of dislocation structure on formation of nanocrystals by mechanical attrition," Materials Science Forum, vol. 179-181, pp. 17-24, 1995.

[32] K. Maung, R. K. Mishra, I. Roy, L. C. Lai, F. A. Mohamed, and J. C. Earthman, "Thermal stability of cryomilled nanocrystalline aluminum containing diamantane nanoparticles," Journal of Materials Science, vol. 46, no. 21, pp. 6932-6940, 2011.

[33] K. Maung, J. C. Earthman, and F. A. Mohamed, "Inverse HallPetch behavior in diamantane stabilized bulk nanocrystalline aluminum," Acta Materialia, vol. 60, no. 16, pp. 5850-5857, 2012.

[34] E. A. El-Danaf, M. S. Soliman, A. A. Almajid, and K. A. Khalil, "Mechanical characterization of cryomilled Al powder consolidated by high-frequency induction heat sintering," Advances in Materials Science and Engineering, vol. 2013, Article ID 397351, 10 pages, 2013.

[35] R. R. Vintila, R. R. L. Drew, and M. Brochu, "Nanostructured NS Al-2024 alloy fabricated by cryogenic milling and consolidated via spark plasma sintering," in Proceedings of the 2010 International Conference on Powder Metallurgy \& Particulate Material, pp. 948-960, Princeton, NJ, USA, 2010. 

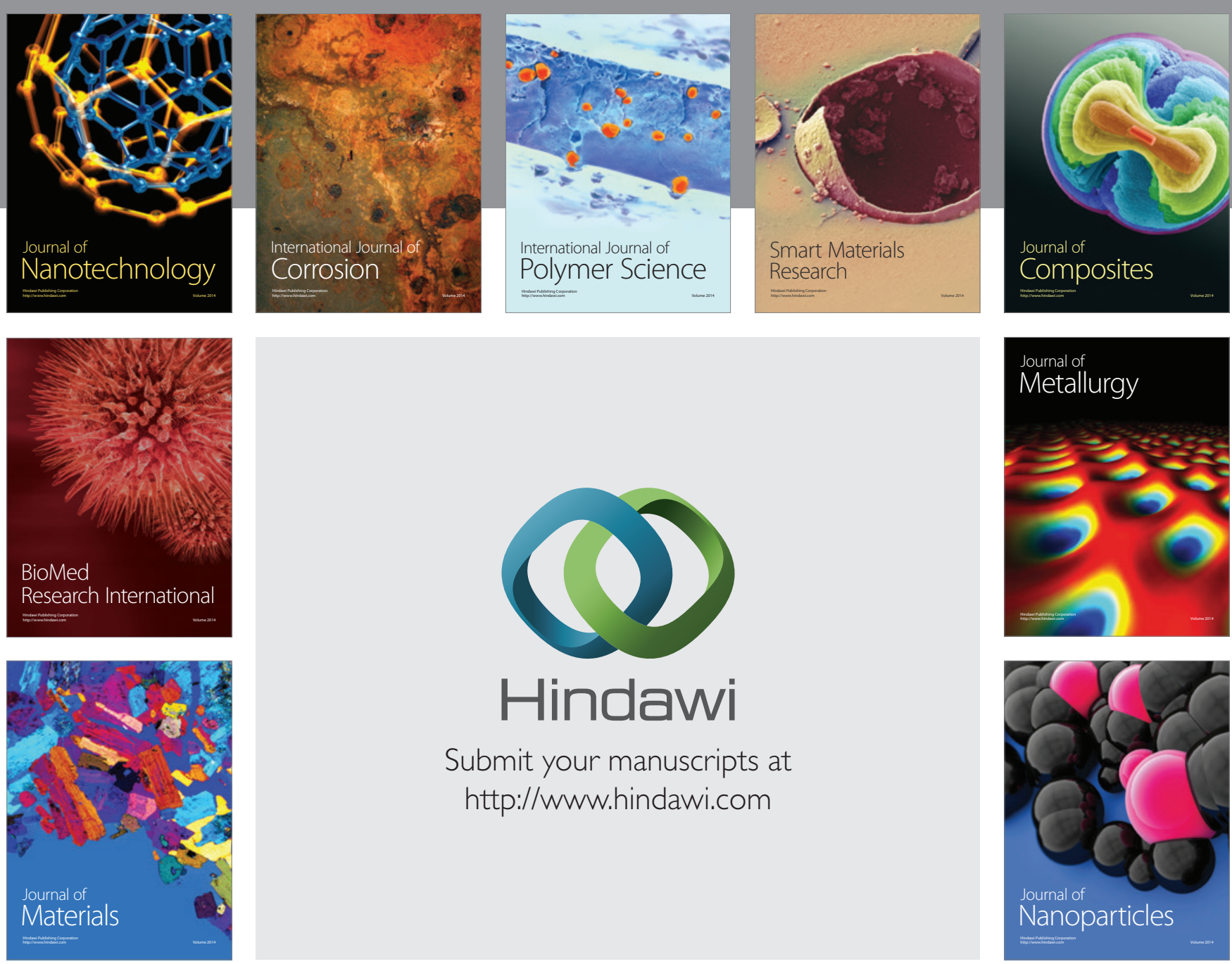

Submit your manuscripts at http://www.hindawi.com
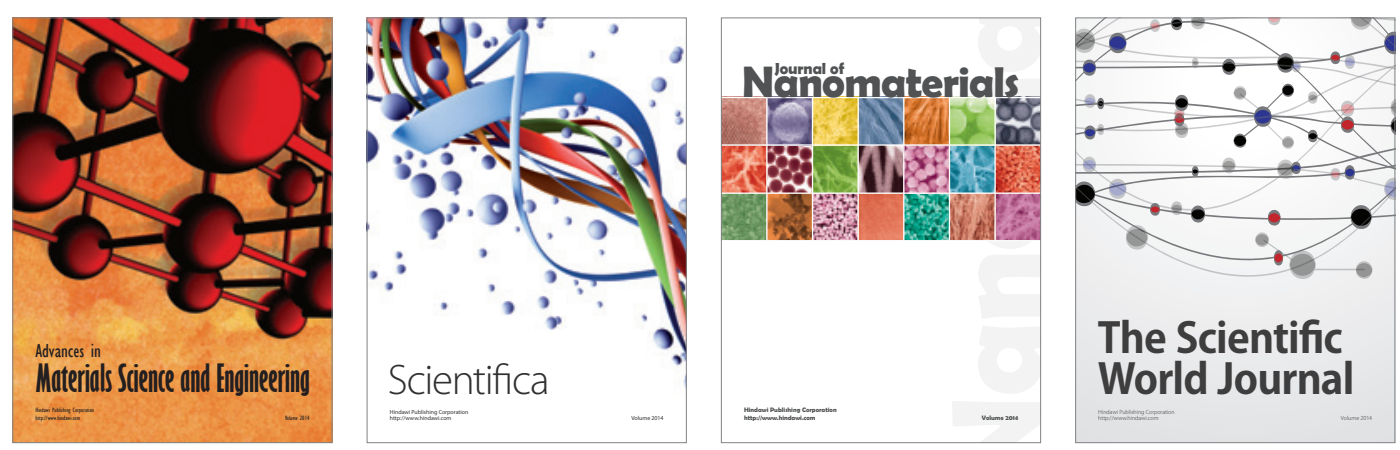

\section{The Scientific World Journal}
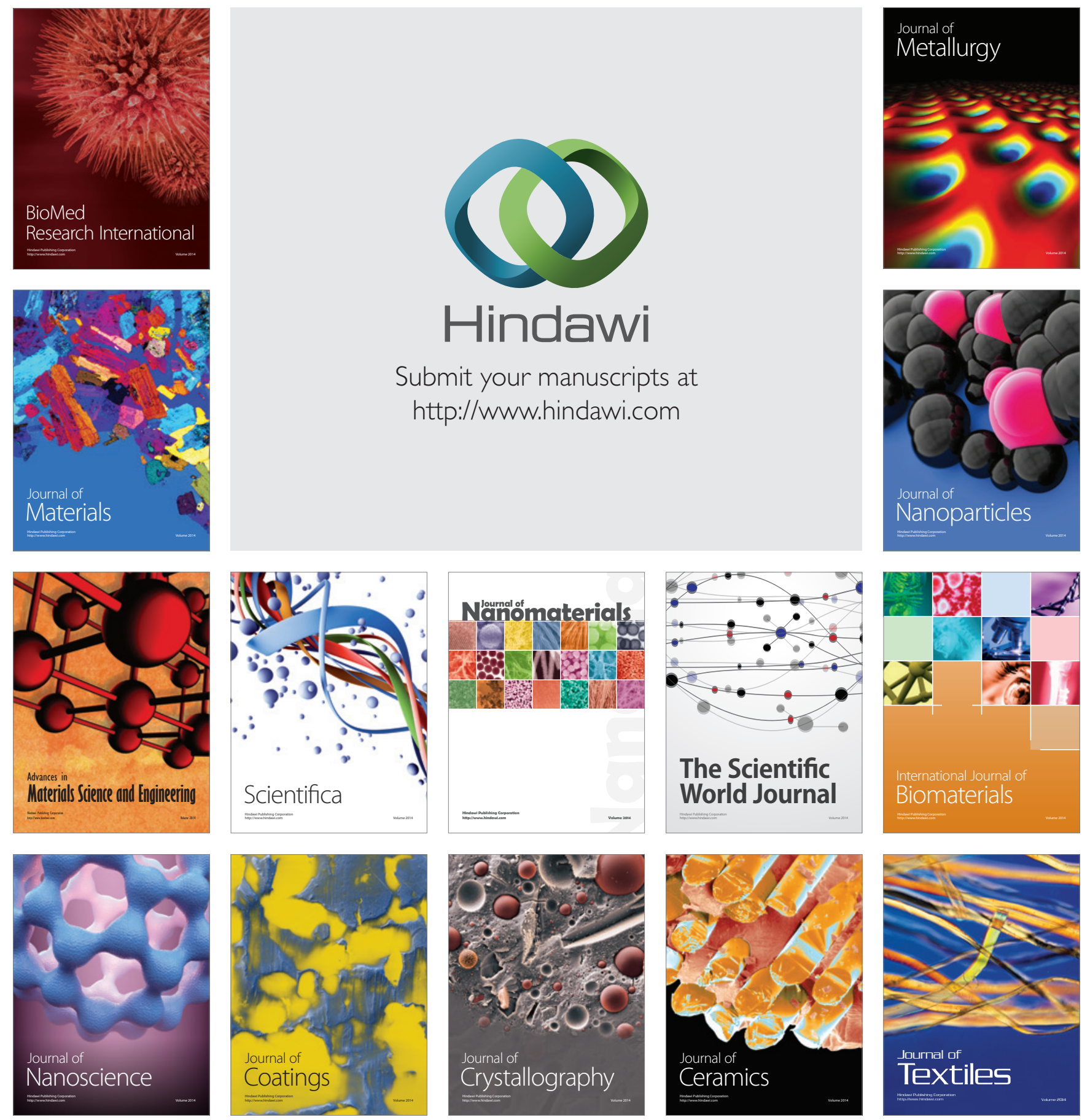